\title{
Political Affections on Online Social Network: The Opinative Priority During the Presidential Campaigns
}

\author{
Aloha Boeck \\ Master in Education, The Lutheran University of Brazil, Canoas, Brazil, alohaboeck@gmail.com
}

\begin{abstract}
How does the urgency on publicizing opinions was expressed in the uses of an online social network during a conflicted period of time like the Presidential Campaign in countries such as Brazil and United States? In these scenarios, it seems that it is not enough to simply reflect on certain relevant topics; it seems essential to externalize opinions that seek to establish an intransigent position. To understand this phenomenon, possible evidence can be found in the way communities of fans are organized, guided by the regulation of affections in the media and in education. Thus, the concept of "opinionative priority" is proposed to understand the disputes about the meaning of democracy that emerge in online social networks, being the attempt to corroborate, counter or refute a statement, in a power dispute. It is the tensioning itself resulting from the need to belong, caused by social networks, and participatory culture, because it is not enough to be and be seen, it is necessary to be part of the discussions, or to initiate a new one. These disputes treat diverse opinions as enemies to be exterminated, obliterating the pluralistic democratic condition, supported by the fundamental right of freedom of speech. Therefore, it is understood that the "opinionative priority" is more than a communication process, since it promotes a pedagogical action in which opinion is formed from absence of moderation, once there is no time for considerations; there is only the urgency to defend a point of view in social networks.
\end{abstract}

KEYWORDS: opinion; online social network; community of fans; democracy, affect

\section{Introduction}

The behavior of people in social networks allows the awakening of an analysis of how important the publication of personal opinions became important. Much motivated by technological ease, it has become a commonplace to comment on all episodes of life in society, sharing other content and integrating a network of interaction. It is not enough just to reflect on certain topics; it seems essential to externalize thoughts and opinions that seek to influence others, an attitude based on the belief that individual opinion has a significant importance in democratic society.

To this new need we call opinative priority, something almost physical that awakens in people the will to express themselves on a certain theme. And to what is called physical, we can approximate the regulations of affection carried out by social networks. "The internet stands out today as the most prodigious archive and court of experiences and emotional manifestations controversial, proscribed or socially legitimized." (Freire Filho 2017, 74). The areas of discussion have expanded and what was circulating in the personal sphere comes to the general level, with opinions and heated debates about politics, society, right and wrong, good and evil, right and left. Criticism goes beyond individual tastes and seeks, at times, to determine collective truths - however unique and univocal.

In this context, there is no need for dialogue or interlocutors, much less incentive. The space of social networks suffices, supported by the ease of a technology that fits in the palm of the hand. That is, conversations that could generate debate nowadays may not even happen. Sometimes they can be silenced, disregarded before they even begin, or can be extended until one of the parties gives up. I say this because, in this concept, the opinative priority is not a search for a conciliatory idea, but a dispute for the sovereignty of the individual view on a certain theme. Although it may agree with other previously expressed opinions, this opinion carries with it the pretension of surpassing everything that has been said with previously, not necessarily by new information, but by the weight of its authorship.

According Recuero (2009), there is an emergency aspect of social networks involving the appearance of large-scale patterns of behavior. In his words, "emergency appears with the arising of collective, non-centralized behavior. As a complex system, the social system will also tend to show 
emerging, collective behavior in this dynamic" $(2009,78)$. That is, the greater the number of people commenting and sharing the same themes, the greater the sense of urgency for others to participate.

As Hall $(2016,260)$ argues, "it is the social actors who use the conceptual, linguistic, and other representational systems of their culture to construct meaning, to make the world comprehensible, and to communicate intelligibly about this world, to others " (49). The social media environment is a powerful tool for this construction, since ideas and opinions circulate in abundance and reinforce meanings and representations. The opinative priority is, therefore, the attempt to corroborate, counter or refute a statement, in a dispute of power - to be able to say, to be able to have more reason. It is the tensioning itself resulting from the need to belong, caused by social networks, and participatory culture, because it is not enough to be and be seen, it is necessary to be part of the discussions, or to base a new one. In this process, those involved need to show and strengthen the visions they advocate in order to override the different ones. It is much less about what to say, but about who has more rights to say, who has the most important opinion.

Generally, this evaluation ends up being individual and, therefore, for the subject, his opinion is the most correct and must, almost obligatorily, come to light. Thus, opinative priority places us in an ambiguous position in which, at the same time as participation is encouraged, it also acts as a form of restriction. It is, at the same time, democratic for its individual rights and censuring for those who oppose it.

Similarly, while roaring encourages others to join in, the speed of internet information creates the habit of quick analysis. The risk lies in the superficiality and lack of development of some manifestations. As a defender of the freedom of speech, I understand that opinion cannot be evaluated on a qualitative scale, but has to be part of an argumentative scale. What is the purpose of saying what was said? How does what was stated contribute to the discussion? What information does opinion bring with itself?

It is also possible to approach the opinative priority to the Dunning-Kruger effect, which demonstrates the difficulty of some people to see that they have no knowledge of a particular subject and, when confronted with people who have more knowledge, are not able to see the difference. According to the study, these people are self-sufficient in their lack of knowledge and respond aggressively to those who know more because they cannot understand that they know less. "In a perfect world, everyone could see the judgments and decisions that other people reach, accurately assess how competent those decisions are, and then revise their view of their own competence by comparison" (Dunning and Kruger 1999, 1131).

Popular participation is also explained from the narrative about the importance of activity in electoral processes. In the Brazilian electoral system, voting is mandatory for citizens between 18 and 70 years old, which forces a choice among most of the country's residents. This obligation has been criticized for years, as many argue that they would not like to choose one of the options presented, as they would not represent them, or discredit the policy presented. The defense of those who believe in the importance of voting is that, even if it was not mandatory, it is necessary to have an opinion and consider the proposals, since the elected candidate will govern anyway. They say that if the decision is inevitable, then the most effective way to have an active participation would be by voting. Exempt does not only nullify the vote but the opinion, so that those who choose this path are diminished in possible claims.

In the United States, one of the most established democracies in the world, voting is not compulsory, which is the basis for those who advocate for voluntary participation. After all, if it works there, why wouldn't it work in other countries?

The year 2018 saw electoral periods in both countries, and both social networks had a large participation. While in Brazil compulsory voting and polarization of campaigns forced their voters to position themselves, in the United States there was a broad campaign to get citizens to the polls. In Brazil, polarization was dividing communities by the opinions that were being published to defend the reasons why, especially, their opponent should not be allowed to win; In the United States, on the other hand, there was a search for young voters, for the diversity at the polls in an attempt to change the current political design. In both cases, the speech was based on the 
fundamental importance of democratic processes in both countries, and how a single voice - or a single vote - can change the outcome. With this, I understand that the opinative priority is not a concept that is born in social networks, but is supported by the technology covered and what it allows. Active participation from the opinion already comes from this view that an individual choice, added to many others, changes the course of the country history, while abstention would be synonymous with invisibility of voice.

The compulsory vote narrative somehow forces the voices to find their counterparts to perhaps form a winning majority. What social networks do, from their visibility imperative, is also to force these voices to show themselves more so they exist and gain relevance. Without technology, conversations could happen in another - more measured, thoughtful, and debated - way. On the Internet and its pages, there is no guarantee of dialogue, or even the need for it to happen. Each opinion is given from its individual sovereignty over that publication space. Therefore, this is how the opinative priority arises, when expressing your opinion publicly is mandatory to live in a democratic process in social networks, electoral or not.

In a society in which social networks play a role as a source of information, opinative priority causes individuals to move beyond their positions in the hierarchy of communication and become major emitters, creating new debates, influencing new discussions, rising on the scale of communication. From this, we have this new concept to support the analysis of participation, since the search is not only to be seen as an individual, but to be respected as an informative source, as a sovereign voice.

\section{Polarizations: the opinative priority in social networks}

Some say that social networks are an example of free and democratic space. In addition to all the technological peculiarities that make these networks tools highly controlled by behavioral information capture algorithms, we must be aware that it is a "clean" place of everything that is not of interest to the user. Each can allow on their profile only what they see as relevant to interact, be it reading, liking, praising or criticizing in comments. Each user creates its own information "box", which circulates the content and discussions to which the user intends to devote some time.

In this aspect, we begin to delineate what could be the democracy defended by the users of social networks: the one in which one chooses the truth that matters, and defends such truth based on the right of freedom of speech. It is the liberal version of the concept of democracy, which is believed that anyone has the right to say what one wants, about who and what suits, whenever she wants, in the possible spaces. The "rest", which individually does not matter, may be disqualified or disregarded as a relevant element to discuss publicly. The freedom to think and say what one thinks is, therefore, a technological tool that circulates these decisions. In a democratic society, it seems fair to be so. On the other hand, democracy is also about the disputes between these individual freedoms, which enters the field of convergence between the public and the private. As in political elections, in social life private choices also have a public reflection: opting for a candidate is a personal decision, the projects implemented in the mandate of the elect influence the whole society: opting to use a few words is a personal decision, but the flow of interpretation and offense that can generate impacts others.

Discussions on social networks often reveal that the choice of the majority is more for personal resolutions than projects for everyone. Thus, it is more interesting to find groups that reverberate the same individualistic thoughts, that demonstrate that they think like an "I", than echo with others who will not value a single voice, seeking something good for "us."

The understanding that today's political decisions are influenced by several factors and that social networks, a space formed mainly by individual interests, plays an important role in the circulation of political information and discussions on this topic, and it is necessary to look back at how these conversations are being conducted. For Mouffe $(2003,11)$, it is a mistake to believe that a "good society" is one without antagonisms. On the contrary, differences are necessary for democracy. Thinking of a common good in this scenario does not mean thinking that what is good 
for one will have exactly the same representation for the other, but seeking a balance for individual interests.

According to a research from 2010, the Brazilian population shows a lack of trust regarding the politicians and the parties, believing more in public and private institutions with hierarchic relations, such as the church and the armed force (Moisés 2010). In this context, to find another people that support the same institutions and the same speeches is a more attractive path for those who wants to participate in political discussions, even if they don't believe in the process. Those individuals come close to the participationist concept, in which they see the digital democracy as a way to promote their voices and to guarantee the sovereignty of the popular opinion (Silva, Sampaio e Bragatto 2016, 24).

Conversely, with the Internet access as an information, knowledge and power source, this instrument becomes a significant part of an individual's socialization process (Freitas 2016, 129). Therefore, in polarized environments, the opinative priority takes action gathering these insights, that endorse the truths being defended by these groups. The democracy protected only by the freedom of speech and for the chance to define the power is the justification for that the opinions can be used as information, decreasing the importance of the technical knowledge.

However, if all opinions have equal weight and value, it does not matter where the knowledge comes from, it is the choice of the majority. And this is where the polarizations that we see in social networks emerge. The reasoning is that, being the individual's opinion and his democratic and sovereign choice, in assuming one truth, the other is automatically disqualified. To both political extremes, the other group is a coup or totalitarian. "Totalitarianism and democracy, Furet taught, are not two opposite truths" (Rancière 2014, 24), and neither are the reasons that lead each group to choose their side.

\section{Opinion in the public sphere of networks}

If the political dispute happens everywhere, all social relations are in some way disputes for space, identification and belonging. This search was not transferred to social networks, only followed the communication flow. Thus, Jürgen Habermas's concept of the public sphere helps to contextualize this dispute, since it considers this a space in which public and private actors discuss public affairs. In theory, this space would contribute to the formation of a public opinion, with a consensus view. However, Gomes (2008) broadens the understanding of the public sphere, and explains it as "the scope of social life in which interests, wills and pretensions that have consequences concerning the political community are presented in the form of argumentation or discussion" (35). Now Barbero highlights the changes from the public sphere defined by Habermas, which included only those who had education and property, to a public sphere "redefined by the presence of urban masses in the social scene, whose visibility refers to the transformation of politics that, from a matter of state, it becomes 'community sphere, sphere of general people's affairs' " (Barbero 2014, 104).

The polarized scenario makes the public sphere to become a producer of equally polarized public opinions, so that the private actor seems to have to choose one side in order to occupy the debate. Therefore, far beyond the exchange of information and reasons, what we see today in social networks is an exchange of public truths produced by each extreme, without consideration.

Still, one cannot disregard the importance of the practice of debate in relation to the political paths that are designed for the future, much less reduce the conversation that occurred in social networks to mere opinionated exposure. The deliberation not only happens in the electoral period, but is under constant construction, especially in the public sphere.

In Brazil, the events of recent years were highly influenced by the participation of social networks, which broadened the scope of information and even helped to "teach" the messages on each side. However, the political division is not new to the country, which has always had its decision-making processes and political movements influenced by the construction of threats, whether communist against the current economic system or elite against social conquests. These speeches often appear in campaigns, building a unique thinking for voters and defenders of particular causes. 
Now the stage is technological as well as decentralized. Instead of using the voices of political actors, it spreads to the voices of public and private figures. Control of political messages in world movements has moved beyond the exclusivity of official institutions and, with networked movements, is increasingly extended to private actors.

And regardless of the debate side, all actors behave similarly on the web and in the arguments, they only change the information in the speeches as appropriate to their truth. Network movements happen mainly in the field of ideas, of discourse. And it is in this field that the limits of freedom of speech and opinion are challenged from the democratic precedent.

\section{Conclusions}

For a long time, the word of formal journalism, the one published in print or on the main news, has been taken as information with the greatest potential for mass influence. Now social networks break through the barrier by letting personal messages, opinions and news circulate with the same weight - scenario harmed by relevance algorithms and message replicator robots.

Nowadays, individuals seem to live with the feeling that they have to choose a side; defend or condemn something; act in group. Although opinions are contrary, the behaviors and strategies of political agents are similar. With no room for the evaluation of the content of what is said or the sides that are chosen, but analyzing the relevance of the chosen characters in their fields - which allows their opinions to assume larger roles than simply reflecting what they think - those involved in the process act in exactly the same way, seeking to reduce the vision of the other side until they can be emptied or even defeated in the electoral process.

In a polarized environment, both sides battle for a larger space and try to overcome opponents to create a "majority". Therefore, the opinative priority is also an indication of what we have been taught about on how to think politically, embedded in a representative democracy that theoretically gives voice to the majority.

If, on the one hand, the public space of social networks could be seen as a "place" for discussions that lead to a consensus view on what is best for most, the comment boxes on these same networks are a "place" to expose an individual view of what each one understands best, and opinative priority becomes an impediment when considering others' view. The pedagogical action of opinative priority is where the lack of moderation is allowed, which does not call for a mature discussion, as there is no time; there is an urgency to speak. Today's social network users seem to understand that their opinion is perhaps the only absolutely free thing left. Thus, it is worth pointing out and reducing the differences to enemies, who deserve to be vigorously fought, making almost nothing noisier than the words written in the comment boxes of social networks.

And it is in this environment that individual opinions and feelings regulate understanding of others' ideals, freedom of speech, and even how much the idea of democracy really matches our behavior as a society. However, just as polarization encourages us to position ourselves, democracy itself may eventually impose the limits of personal opinion, so that it is understood that, although important, it is not sovereign and not true only by desire; to understand that we can be, as a society, more than this noisy tangle of different opinions, fighting for power.

\section{References}

Barbero, Jesús Martin. 2014. The Communication on Education. São Paulo: Contexto.

Dunning, David and Kruger, Justin. 1999. "Unskilled and Unaware of It: How Difficulties in Recognizing One's Own Incompetence Lead to Inflated Self-Assessments.” Journal of Personality and Social Psychology 77(6): 121-1134. Accessed November 25, 2018. https://pdfs.semanticscholar.org/e320/9ca64cbed9a441e55568797cbd3683cf7f8c.pdf.

Freire Filho, João. 2017. "Chains of happiness: emotions, gender, and power.” MATRIZes 11(1): 61-81.

Freitas, Cristiana Soares de. 2016. The simbolical domination mecanisms on the networks of digital political participation. Conceptions, discussions and the digital democracy challenges. Digital democracy, political communication and networks: theory and pratical. Rio de Janeiro: Folio DigitaL: Letra e Imagem. Rancière, Jacques. Hatred of Democracy. 1. ed. São Paulo: Boitempo, 2014.

Gomes, Wilson and Mais, Rousiley C. M. 2008. Communications and Democracy: Problems and Perspectives. São Paulo: Paulus.

Hall, Stuart. 2016. Representation. Rio de Janeiro: PUC-Rio: Apicuri. 
Moises, José Álvaro. 2010. “The Meanings of Democracy according to Brazilians.” Campinas: Opinião Pública 16(2): 269-309. Accessed July 11, 2019. http:/www.scielo.br/scielo.php?script=sci_arttext\&pid=S0104$62762010000200001 \& \operatorname{lng}=\mathrm{en} \& \mathrm{nrm}=$ iso.

Mouffe, Chantal. 2003. "Democracy, citizenship and the pluralism question." Politics \& Society: The Political Sociology Magazine, Florianópolis, 3:11-26

Recuero, Raquel. 2009. Social media on the Internet. Porto Alegre: Editora Sulina. 191 p. Accessed May $10,2018$. http://www.revistas.usp.br/matrizes/article/view/122954/127912

Silva, Sivaldo Pereira da, Sampaio, Rafael Cardoso, and Bragatto, Rachel Callai. 2016. Conceptions, discussions and the digital democracy challenges. Digital democracy, political communication and networks: theory and practice. Rio de Janeiro: Folio DigitaL: Letra e Imagem. 